\title{
Body skin hyperlaxity due to vitamin K- dependent coagulation factor deficiency
}

INSERM

\section{Source}

INSERM. (1999). Orphanet: an online rare disease and orphan drug data base. Body skin hyperlaxity due to vitamin K-dependent coagulation factor deficiency. ORPHA:91135

Body skin hyperlaxity due to vitamin K-dependent coagulation factor deficiency is a very rare genetic skin disease characterized by severe skin laxity affecting the trunk and limbs. 